\title{
The Physical Impact of Spina Bifida in an Irish Population
}

\author{
Culligan E1, Governey $\mathrm{S}^{2}$ * and Leonard J ${ }^{3}$ \\ ${ }^{1}$ Department of Physiotherapy, Tallaght Hospital, Ireland \\ 2Department of Occupational Therapy, Temple Street Children's Hospital, Ireland \\ ${ }^{3}$ Consultant Paediatrician, Temple Street Children's Hospital, Ireland
}

*Corresponding author: Sarah Governey, Department of Occupational Therapy,

\section{Research Article \\ Volume 2 Issue 2}

Received Date: April 17, 2019

Published Date: May 28, 2019

DOI: $10.23880 /$ aphot- 16000127

Temple Street Children's Hospital, Ireland, Tel: +353 18784542; Email: sarah.governey@cuh.ie

\section{Abstract}

The aim of this study is to review the physical needs experienced by children with spina bifida (0-18 years) in Ireland. Ireland has one of the highest rates of Neural Tube Defects (NTDs) in the world and is therefore an ideal population to study. 155 parents/guardians completed purposively designed quantitative questionnaires. Results were analyzed using descriptive statistics including frequency distributions, measures of central tendency using excel; and bivariate relationships using SPSS. Physical presentation of this complex condition impacts on many aspects of children's lives. The most prevalent level of spinal lesion was lumbar (27\%) followed by lumbosacral (19\%) and sacral (12\%). 64\% of children have a Cerebrospinal Fluid (CSF) shunt in situ. 69\% of children required a wheelchair for mobility. Orthopaedic complications are high at $78 \%$, increasing to $90 \%>10$ years. $84 \%$ of all children required interventions to support their continence and urological health which increased to $93 \%$ for school aged children. Nearly all body systems are affected and require support. Although the underlying disability is present from birth, the implications and secondary complications of SB can be significant.

\section{What this paper adds}

- Physical impact of Spina Bifida in the Irish Population

- Orthopaedic complications and surgery rate $90 \%$ in over 10 years

- Bladder / Bowel incontinence present in over $85 \%$ of population

Keywords: Spina Bifida; Orthopaedic Complications; Bladder/Bowel

Abbreviations: SB: Spina bifida; NTD: Neural Tube Defects; CSF: cerebrospinal fluid; TSCUH Temple Street Children's University Hospital; SBHI: Spina Bifida Hydrocephalus Ireland; TOPFA Termination of Pregnancy for Fetal Anomaly; BMI: Body Mass Index; LMS: Least Mean Square; CIC: Clean Intermittent Catheterization.

\section{Introduction}

Spina bifida (SB), is a type of neural tube defect (NTD), which has been described as the most complex congenital abnormality compatible with life which presents with a variety of complications [1,2]. Antibiotic and surgical advances in the last half century have improved life 


\section{Annals of Physiotherapy \& Occupational Therapy}

expectancy which often used to be less than a year. Improvements in the management of infants, children, adolescents and adults with SB and hydrocephalus have meant that many are now not only surviving into adulthood, but live active and happy lives $[3,4]$.

The impact of SB on the child and family can be substantial and complex. Multiple body systems are affected to some degree depending on the level of the lesion. This includes paralysis of the lower limbs below the level of lesion, anaesthesia of the skin as well as contractures or abnormalities of the lower limbs [5]. Hydrocephalus and Chiari Type II malformations are common [3]. Children with SB frequently require the insertion of a cerebrospinal fluid (CSF) shunt for the management of hydrocephalus which can be present in up to $80 \%$ of cases [5]. Almost all individuals with SB will have some degree of bladder and bowel dysfunction because the low sacral nerves innervate the distal bowel, anal sphincter, bladder and internal and external bladder sphincters [6]. Secondary complications of such as obesity, scoliosis, pressure sores, reduced independence and restricted participation in school and society can also have considerable impact on the child and family as described by Simeonsson RJ [7].

Ireland has one of the highest rates of NTDs in the world with an incidence of 1.17 per 1000 , about half of whom present with SB [8]. Northrup and Volcik [5] report a variation in incidence by ethnicity with the Celtic nations specified as having high incidence compared to North America. Although no central database exists for incidence of children with SB in Ireland, calculations based on the European Surveillance of Congenital Anomalies [9] data, Temple Street Children's University Hospital (TSCUH) and Spina Bifida Hydrocephalus Ireland (SBHI) reported numbers, and incidence and birth rates would suggest that there are approximately 500 children (0-18 years) with SB currently in Ireland. Reasons cited for high rates of SB in Ireland include a genetic predisposition, a history of low peri-conceptual folic acid intake and the fact that termination of pregnancy for fetal anomaly (TOPFA) was not legal $[8,10]$. A high incidence of SB in the Irish population makes it an ideal population to study. The demographics, primary implications in relation to mobility, level of lesion, requirements of therapy and surgical interventions as well as secondary complications such as obesity, pressure sores and psychosocial impact will be reviewed in this study and compared to international studies. The specific objectives are to review the physical profile and consequent interventions required to support these children. A questionnaire identifying the physical presentation and needs of SB was not identified in the literature.

\section{Methods}

The overall aim of the study was to identify the demographics and profile of children aged 0-18 with SB in Ireland and to review the physical consequences and implications of this condition. A mixed method sequential explanatory design was utilized, consisting of three phases, collecting data from three different population groups (service providers, parents / guardians, children 8-18 years). Quantitative questionnaires were completed then followed up by in-depth interviews to further explore these results. Only results from parent/guardians are represented in this article. The research was funded by the Children's Fund for Health, Temple Street Fundraising department, and ethical approval was obtained from Temple Street Research and Ethics Committee.

A purposive sampling method was employed to gather information from parents/guardians of children aged 018 years with spina bifida. Community pediatricians, SBHI, and the national SB clinic service acted as gatekeepers to distribute paper based questionnaires via post to their client base. Electronic versions of the questionnaire were also made available for ease of completion. Only one parent / guardian response per child was accepted. Responses were received from 155 parents/guardians which represents a response rate of $32 \%$ of the overall estimated national population of children with SB in Ireland. Questionnaires were purposively developed by the research team as no questionnaire was identified in the literature capturing the range of demographic and physical profile required. This questionnaire (see appendix) was reviewed by MDT peers for readability. The data presented in this article are from the demographic and medical information sections. Questions were closed ended dichotomous with Likert scales as well as qualitative comments. The period of data collection ran from June 2014 to December 2014 with analysis occurring until April 2015.

Quantitative data was coded, anonymized and analyzed with descriptive statistics including frequency distributions, measures of central tendency and bivariate relationships using SPSS. Results related to the physical impact of SB on the child will be presented in this article.

\section{Results}

155 parent/guardian respondents reported on the physical impact and profile of their child with SB. The demographics of the respondents and the children represented are presented in Table $1.86 \%$ of respondents 


\section{Annals of Physiotherapy \& Occupational Therapy}

were mothers, $12 \%$ fathers and $2 \%$ guardians / foster parents. $96 \%$ of children were of Caucasian ethnicity. The child's ages, as reported by the parent / guardians ranged from 2 months to 18 years, with a mean of 5.7 years.
Although sampling methods aimed to capture all children in the 0-18 year age range, a greater number of young children were represented.

\begin{tabular}{|c|c|c|c|c|}
\hline Respondents & Mother & Father & Foster parent & Registered guardian \\
\hline & $86 \%(\mathrm{n}=133)$ & $12 \%(\mathrm{n}=19 \%)$ & $1 \%(\mathrm{n}=1)$ & $1 \%(\mathrm{n}=1)$ \\
\hline Child's Age & Mean 5.7 years & \multicolumn{2}{|c|}{ Range 2 months -18 years } & \\
\hline & Over 3 years $\mathrm{n}=93$ & \multicolumn{2}{|c|}{ Over 5 years $\mathrm{n}=65$} & Over10 years $\mathrm{n}=32$ \\
\hline Child's gender & Male 46\% $(\mathrm{n}=69)$ & Female $54 \%(\mathrm{n}=81)$ & Ratio: $1: 1.17$ & Eastern European \\
\hline Child's Ethnicity & White Ethnicity & Black & Asian & $(\mathrm{n}=1)$ \\
\hline & $96 \%(\mathrm{n}=148)$ & $2 \%(\mathrm{n}=3)$ & $(\mathrm{n}=1)$ & \\
\hline
\end{tabular}

Table 1: Demographics.

The range of physical presentation, impairments and interventions within the sample population are represented in percentages in Table 2. The level of lesion can be significant in predicting the physical presentation. Of note, a very large proportion of parents (34\%) were unsure of the level of their child's lesion. Of those that did report the level of lesion, the largest proportion of children had a lumbar lesion (27\%) followed by lumbosacral (19\%) and sacral (12\%). Sixty three percent of the sample had CSF shunts inserted for management of hydrocephalus, almost all being inserted in the first 6 months of life.
In relation to the impact of SB on physical function, seventy eight percent of parents indicated that their child had an orthopedic complication. These included fracture, hip dislocation, foot and ankle deformities, contractures, spinal deformities. The rate of orthopedic complication increased to $90 \%$ for children aged over 10 years. Half of the sample had undergone orthopedic surgery of some kind; however in the children aged over 10 years of age, $87 \%$ had required orthopedic surgery.

\begin{tabular}{|c|c|c|c|}
\hline & & $\mathbf{N}$ & $\%$ \\
\hline \multirow{7}{*}{ Level of Lesion } & Cervical & 1 & 1 \\
\hline & Thoracic & 5 & 3 \\
\hline & Thoracolumbar & 6 & 4 \\
\hline & Lumbar & 39 & 27 \\
\hline & Lumbosacral & 28 & 19 \\
\hline & Sacral & 17 & 12 \\
\hline & Unknown & 49 & 34 \\
\hline \multirow{5}{*}{ VP Shunt Inserted } & First week of life & 42 & 28 \\
\hline & First 6 months & 48 & 32 \\
\hline & First 2 years & 4 & 2.7 \\
\hline & After 2 years old & 1 & 0.7 \\
\hline & No Shunt inserted & 54 & 36 \\
\hline \multirow{2}{*}{ Orthopedic complications } & All sample & 103 & $78 \%$ \\
\hline & Over 10 years & 26 & $90 \%$ \\
\hline \multirow{2}{*}{ Orthopedic Surgery } & All sample & 73 & $55 \%$ \\
\hline & Over 10 years & 26 & $87 \%$ \\
\hline \multirow{2}{*}{ Bladder and Bowel dysfunction } & All sample & 111 & $84 \%$ \\
\hline & Over 5 years & 55 & $93 \%$ \\
\hline \multirow{5}{*}{$\begin{array}{c}\text { Bladder and Bowel interventions (over } \\
5 \text { years) }\end{array}$} & Nappies & 49 & $83 \%$ \\
\hline & Clean Intermittent Catheterization & 40 & $67 \%$ \\
\hline & Medication (excluding antibiotics) & 30 & $50 \%$ \\
\hline & Prophylactic antibiotics & 16 & $27 \%$ \\
\hline & Surgery & 8 & $13 \%$ \\
\hline
\end{tabular}

Table 2: Physical presentation, impairments and interventions. 
In relation to bladder and bowel dysfunction, $84 \%$ of all children required interventions to support their continence and urological health. This percentage increased to $93 \%$ for school age children (over 5 years when social continence is expected). The management strategies are detailed in Table 2.

Figure 1 (below) details the physical presentation of children with SB in relation to family history and the need for a CSF shunt. Early closure of the lesion requires neurosurgical intervention and $64 \%$ had a CSF shunt inserted for management of hydrocephalus. Of note, $20 \%$ of the sample reported a positive family history of neural tube defects. Figures 2 and 3 highlight some of the physical needs and secondary complications of SB on the respondent's children and represents the complexity of needs affecting multiple body systems at key stages of childhood, many of which may require surgery and interventions throughout childhood to manage. Contractures and orthopaedic deformities of the spine and lower limbs resulted in $87 \%$ requiring orthopaedic surgery by age 10 . Mobility impairment is significant with $69 \%$ of children requiring a wheelchair at age $3.83 \%$ were dependent on nappies to support their incontinence at school age. $19 \%$ suffered pressure sores due to impaired sensation.

Obesity rates as a secondary complication were high. Parent / Guardians reported their child's height and weight within the questionnaire. The Body Mass Index (BMI) and BMI centiles were calculated using Least Mean Square (LMS) growth software. UK growth curves classify a child as overweight if BMI is $>91$ st. Obesity is classified as a BMI $>97$ th centile. $30 \%$ of the sample was obese, with $6.5 \%$ being morbidly obese.

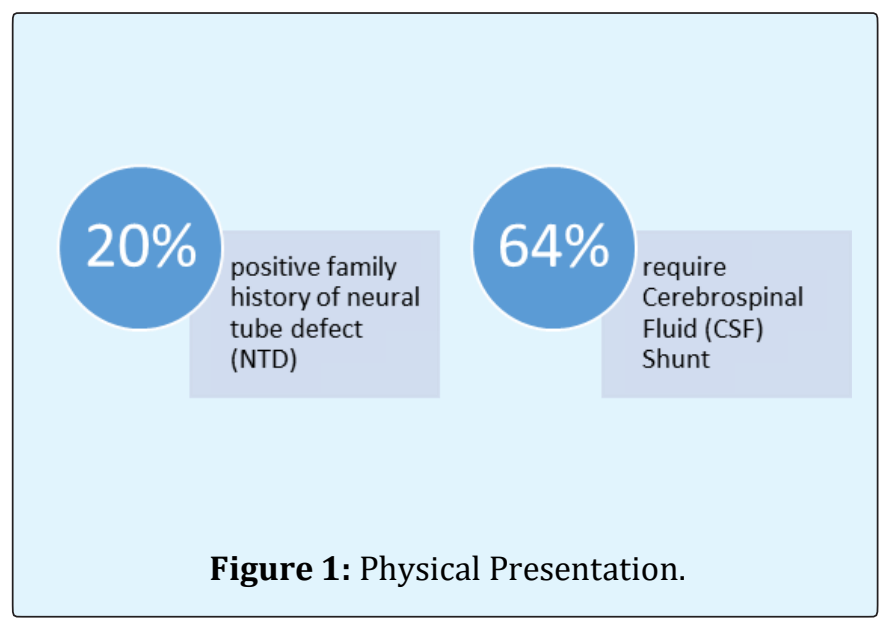

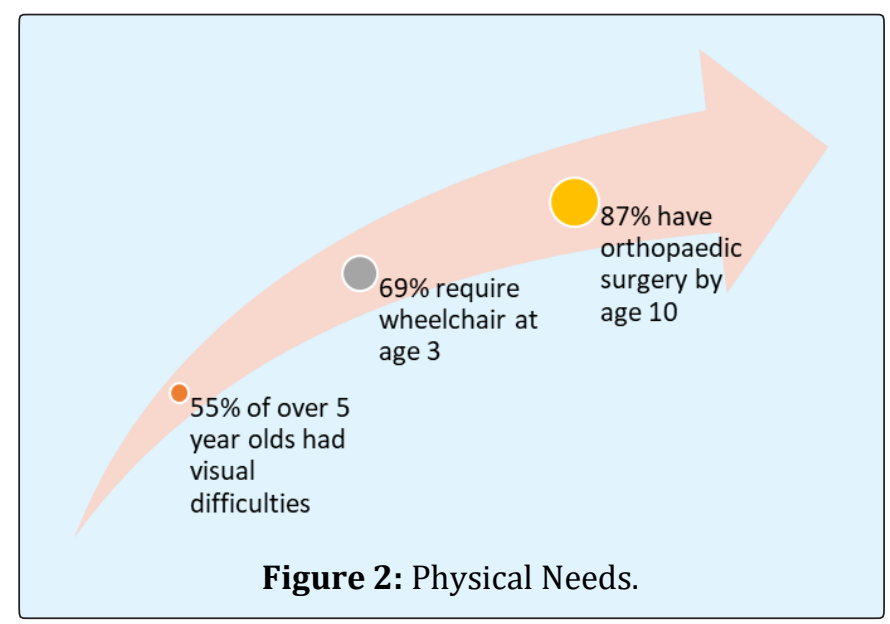

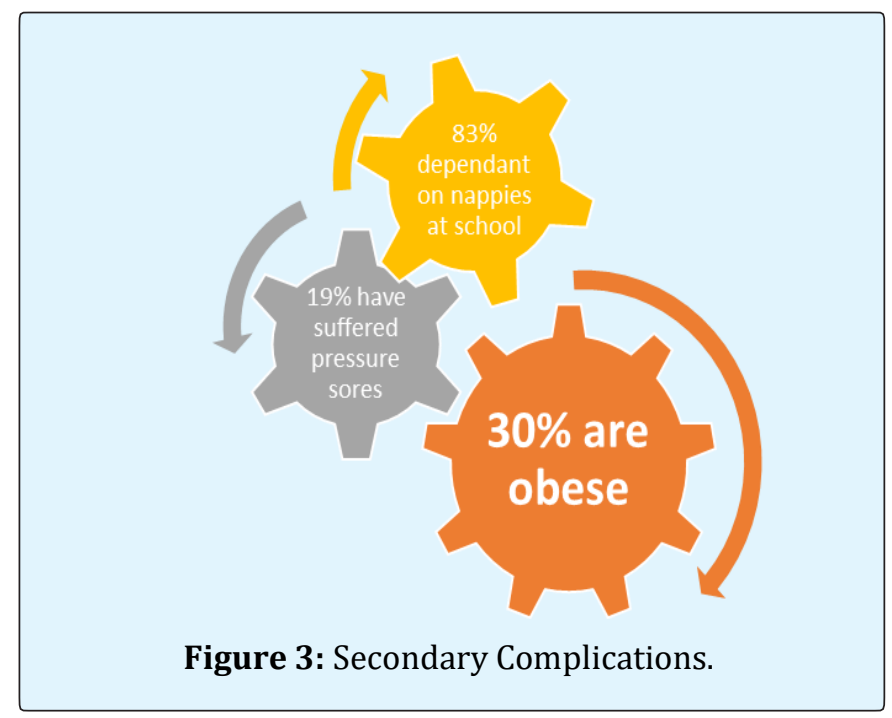

Table 3 details the mobility level of the children over 3 years when mobility potential is expected to be established. $69 \%$ of parents noted that their child is a wheelchair user either all or most of the time, and only $5 \%$ walked without splints. The remaining $24 \%$ have equipment dependent mobility requiring a variety of splints / aids and mobility aids.

The children in this sample had high requirement for equipment with a wide variation of equipment in place. Eighty three per cent of parents indicated that they have received equipment of some sort to support their child. The most frequently received pieces of equipment being those relating to assisting mobility - Orthoses (76\%), standing frames (64\%), manual wheelchairs (61\%), and mobility aids (54\%). Of note only $2 \%$ of the children had a power chair. 


\begin{tabular}{|c|c|c|c|}
\hline Mobility Level aged over 3 years (n=93) & \multicolumn{2}{|c|}{ Equipment Use } \\
\hline Too young & $2 \%$ & Orthotics & $76 \%$ \\
\hline Wheelchair all or most of the time & $49 \%$ & Standing frame & $64 \%$ \\
\hline Mobile sometimes wheelchair sometimes & $20 \%$ & Manual Wheelchair & $61 \%$ \\
\hline Walks with splints and needs help & $7 \%$ & Mobility Aids & $54 \%$ \\
\hline Walks with splints and aids & $17 \%$ & Shower / bath chairs & $40 \%$ \\
\hline Walks independently & $5 \%$ & Activity chair & $29 \%$ \\
\hline & & Sleep system & $18 \%$ \\
\hline & & Power chair & $2 \%$ \\
\hline
\end{tabular}

Table 3: Mobility and equipment needs.

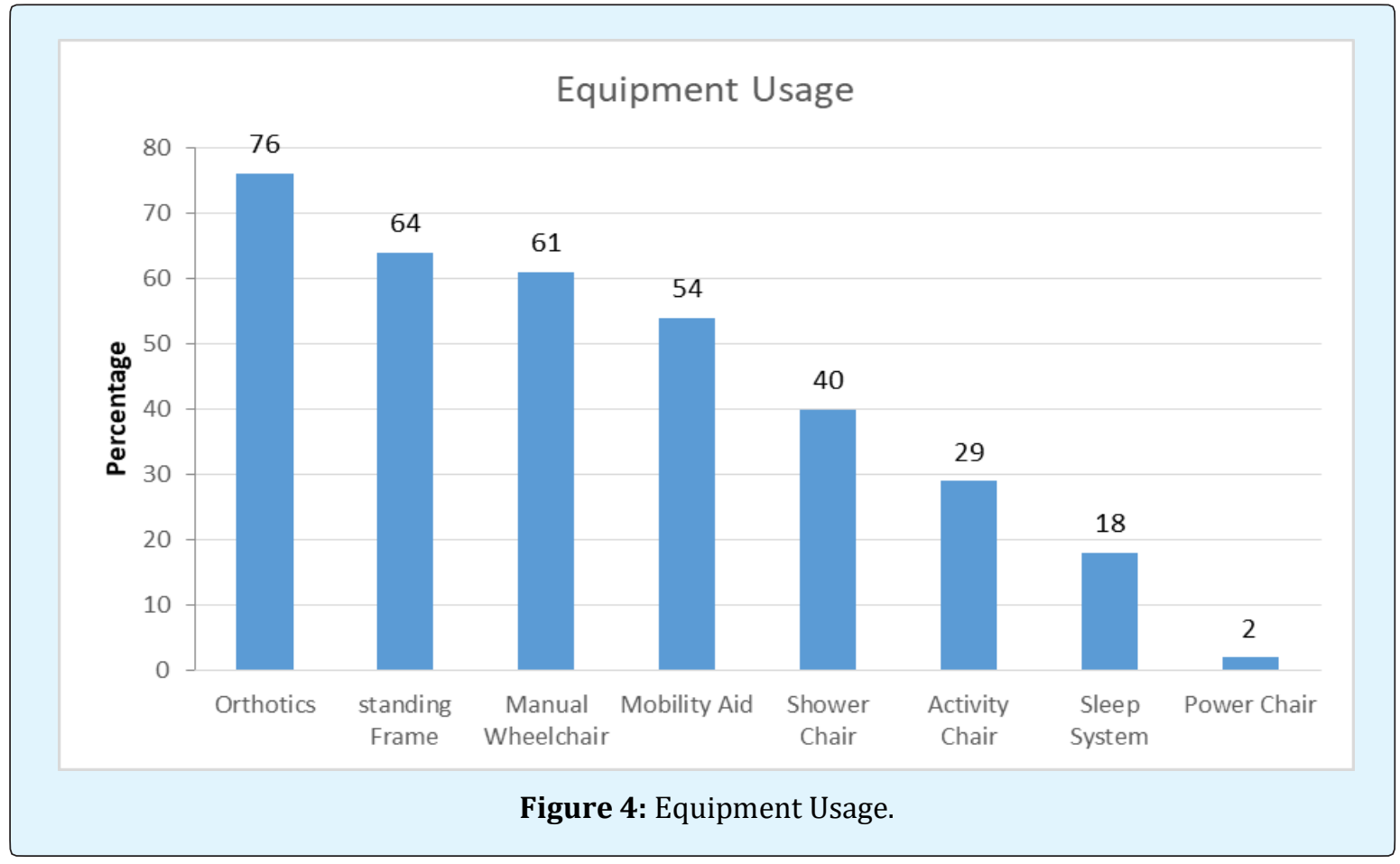

\section{Discussion}

The range of results reported within this study demonstrates the complex physical presentation and needs of this population in the Irish setting. These children with SB have physical impairments and needs ranging from neurosurgical, orthopedic, urological, to tissue viability, growth and nutrition, equipment, mobility and visual. Nearly all body systems are affected and require support. Although the underlying disability is present from birth, the implications and secondary complications can be significant.

A strong family history of neural tube defects was noted in this sample $(20 \%)$ as compared to previous studies in the Irish context [11] who reported an adverse pregnancy outcome in $17.4 \%$ maternal first cousins of SB, although outcomes included preterm deliveries, stillbirths, and miscarriages. McDonnell, et al. [8] reported a genetic predisposition for increased risk of SB in Ireland and this warrants further investigation.

The number of children with CSF shunts in situ in this study (64\%) are lower than historical reports of $86 \%$ in a 25 year prospective study in the USA [12]. However they appear to be in line with more up to date literature which recommends a more conservative approach to shunt insertion with rates as low as $52 \%$.

The level of lesion can be a predictor for ultimate function and mobility. The pattern of muscle weakness and mobility level will vary with each individual, depending upon the site and extent of the spinal defect [3]. The mobility potential for children with SB is significantly 


\section{Annals of Physiotherapy \& Occupational Therapy}

related to the presence of quadriceps power (functional lesion level L3/4 or below) [13-16]. 34\% of the sample did not know the level of lesion of their child which is of concern and makes direct comparison with other studies difficult. Given the relevance of this information to parents, this should be improved. Reported international studies all cite the lumbosacral region as most predominant; and the proportion of lesions per group are comparable to previous studies internationally when the 'unknowns' are removed for comparison [17-20].

The onset of walking in children with SB has been reported to be delayed by an average of 2 years and continues to develop until 6 years of age $[21,22]$. The data relating to mobility in this study was therefore analyzed for children aged 3 and above to ensure they had the time to reach their mobility potential. At this stage mobility potential was established for $98 \%$ of children indicating that this age is appropriate to review. Only 5\% were independently mobile without equipment, the remaining required equipment to achieve mobility (wheelchair 69\%, splints 24\%). This highlights the need for specialist orthotics, mobility aids and wheelchairs for this population, and the staff to assess and provide appropriate equipment in a timely manner to promote independence. As health-related quality of life is reported to be significantly associated with mobility for children with SB the provision of equipment to support independence is vital [23]. The results from this study detail a high overall equipment use, the majority of which is mobility related (orthotics, standing frames, wheelchairs, mobility aids). Interestingly only $2 \%$ of the sample had a power chair, this may be related to the relatively young sample (mean age 5.7 years). Other equipment listed as frequently in use were bath shower chairs (used by $40 \%$ ), activity chairs (used by 29\%) and sleep systems (used by 18\%).

The most common orthopedic complications associated with SB are hip dysplasia or dislocation, scoliosis, and foot and ankle deformities. Scoliosis has been reported to be present in as many as 52\% of children with SB $[24,25]$. Orthopedic complication and surgical rates are high in this sample with $78 \%$ of all sampled reporting an orthopedic complication, and 55\% having undergone orthopedic surgery. Surgical complications and time of intervention are discussed in the literature. Most foot deformities, although initially treated with the Ponseti method will require surgical intervention which is recommended early irrespective of weight-bearing status [26]. Wright [27] in a large review of orthopaedic literature reported that there is a lack of level 1 evidence in this area. The conclusions indicated that hip reduction surgery may be appropriate in low- level unilateral dislocations to promote continued mobility. Other orthopaedic complications such as fractures and progression of scoliosis are also more common in later childhood. Children with SB are predisposed to fracture of their lower extremities more commonly in early adolescence [28]. Scoliosis has the potential to cause pelvic obliquity, spinal imbalance, seating difficulties, and in the long-term pulmonary dysfunction. It requires vigilance and monitoring throughout the growing years with ultimate fusion to achieve a level pelvis with a balanced spine in both coronal and sagittal planes [29]. In order to determine the increasing need in the early adolescent phase, the data was reviewed for the oldest cohort in the sample (over 10 years). At this stage the complication rate has increased to $90 \%$ and the surgical rate increased to $78 \%$ demonstrating an increased demand for orthopaedic services in the adolescent phase. The needs and complexity of surgical intervention increase with age. Orthopedic evaluation is required for all children with SB to ensure a good functional outcome and quality of life.

Almost all individuals with SB will have some degree of bladder and bowel dysfunction because the low sacral nerves innervate the distal bowel, anal sphincter, bladder and internal and external bladder sphincters which are rarely spared [6]. Early urological evaluation and appropriate monitoring and interventions are essential to protect renal function and promote continence. According to Merkens guidelines for the management of SB [30]; all preschoolers should have bowel and urine programs in place to establish social continence and by school age continence should be well established. Therefore the data relating to bladder and bowel dysfunction and interventions in this study was analyzed for children aged 5 and above. This study reveals that $93 \%$ of school aged children sampled a reported bladder and bowel difficulty which is expected due to the nature of the spinal dysfunction. Looking at the interventions that were in place to support this in this age group, $67 \%$ were using clean intermittent catheterization (CIC) which compare favourably with previous studies reporting a rate of $65 \%$ Clayton, et al. [31]; Verhoef, et al. [32]. Nappy use to support continence was high at $83 \%$, this can have significant impact for both the family and child in terms of dependence and psychological well-being. The practice of prophylactic antibiotic treatment for children undergoing clean intermittent catheterisation for neurogenic bladder is well documented in the literature. Dik, et al. [33] and Verhoef, et al. [32] report that $30 \%$ of adult SB patients were on continuous antibiotics and $62 \%$ had taken high dose antibiotics within the last year to manage a UTI. The prophylactic antibiotic use reported here was $27 \%$ which matches these figures. Other medications listed were 


\section{Annals of Physiotherapy \& Occupational Therapy}

related to management of motility and constipation with $50 \%$ of the sample taking some form of medication in addition to antibiotics.

Concerns regarding the significance of obesity in the SB population have been reported as early as the 1970 s by Hayes-Allen and Tring [34]. The prevalence of obesity in SB has been reported to range from $18 \%$ to as high as $58 \%$ [35-38]. Overall $30 \%$ of the sample was classified as obese. This is 5 times greater than the reported rates in the typically developing population [39]. The additional burden of obesity on this already vulnerable population is significant. As children born with SB can now expect to survive well into adulthood [12], health promotion is important to optimize health in adult life. Inactivity, obesity and reduced physical fitness can increase the likelihood of secondary conditions including hypertension, emotional wellbeing and quality of life $[40,41]$.

\section{Conclusion}

Overall, the physical impact is wide and varied for this population as represented by these figures. A large study population of 155 allows for more generic comparison and should aid in anticipating the needs and determining service interventions and timeframes for those involved in service planning and provision. The limitations of this study include the use of a purposively designed selfreporting questionnaire however no existing appropriate measure existed which would capture the extent of data required by this study. Another limitation was the purposeful sampling method. No central database exists for all patients with SB in Ireland; therefore all attempts were made to access through national pediatricians and SBHI. Although 32\% response rate is high for a postal questionnaire there may be bias in self-selection for inclusion. This study contributes to the evidence about the physical impact of SB with extensive data regarding this complex population in a unique population with a large incidence.

\section{Conflicts of Interest: None to report}

\section{Acknowledgement}

With special thanks to Ms. Judith O'Connell, Ms. Amy Faulkner, Mr. Darach Crimmins, Mr. Paul Connolly, Mr. Thambipillai Sri Paran, the Spina Bifida Team, Occupational Therapy and Physiotherapy Departments of Temple Street Children's University Hospital, the gatekeepers, service providers and families who gave their time, knowledge and interest to participate and make this research possible.
Funding: The research was funded by the Children's Fund for Health, Temple Street Fundraising department.

\section{References}

1. Liptak GS, El Samra A (2010) Optimizing health care for children with spina bifida. Dev Disabil Res Rev 16(1): 66-75.

2. Liptak G (2003) Evidence-Based Practice in Spina Bifida: Developing a research agenda. Spina Bifida Association of America, (Ed.), Centers for Disease Control and Prevention, Atlanta, Georgia Agency for Healthcare Research and Quality, Rockville, Maryland National Institutes of Health, Bethesda, Maryland.

3. Crosthwaite A, Chuchyard A, Williams R, Wells J, Donellen S, et al. (2001) Spina Bifida Overview. Victoria, Spina Bifida Foundation of Victoria, Australia.

4. Shin M, Kucik JE, Siffel C, Lu C, Shaw GM, et al. (2012) Improved survival among children with spina bifida in the United States. Journal of Pediatrics 161(6): 1132-1137.

5. Northrup H, Volcik KA (2000) Spina bifida and other neural tube defects. Curr Probl Pediatr 30(10): 313332.

6. Shaer CM (2007) The infant and young child with spina bifida: major medical concerns. Infants \& Young Children: An Interdisciplinary Journal of Special Care Practices 9: 13-25.

7. Simeonsson RJ, Mcmillen JS, Huntington GS (2002) Secondary conditions in children with disabilities: spina bifida as a case example. Ment Retard Dev Disabil Res Rev 8(3): 198-205.

8. Mcdonnell R, Delany V, Omahony MT, Mullaney C, Lee B, et al. (2014) Neural tube defects in the Republic of Ireland in 2009-11. J Public Health 37(1): 57-63

9. EUROCAT Working Group (1991) Prevalence of neural tube defects in 20 regions of Europe and the impact of prenatal diagnosis, 1980-1986. J Epidemiol Community Health 45(1): 52-58.

10. Food Safety Authority of Ireland (2008) Report of implementation group on folic acid food fortification to the department of health and children Dublin.

11. Byrne J, Carolan S (2006) Adverse reproductive outcomes among pregnancies of aunts and (spouses 


\section{Annals of Physiotherapy \& Occupational Therapy}

of) uncles in Irish families with neural tube defects. American Journal of Medical Genetics 140(1): 52-61.

12. Bowman RM, Mclone DG, Grant JA, Tomita T, Ito JA, et al. (2001) Spina bifida outcome: a 25-year prospective. Pediatr Neurosurg 34(3): 114-120.

13. Danielsson AJ, Bartonek A, Levey E, Mchale K, Sponseller P, et al. (2008) Associations between orthopaedic findings, ambulation and health-related quality of life in children with myelomeningocele. J Child Orthop 2(1): 45-54.

14. Mcdonald CM, Jaffe KM, Mosca VS, Shurtleff DB (1991) Ambulatory outcome of children with myelomeningocele: effect of lower-extremity muscle strength. Developmental Medicine \& Child Neurology 33(6): 482-490.

15. Huff CW, Ramsey PL (1978) Myelodysplasia. The influence of the quadriceps and hip abductor muscles on ambulatory function and stability of the hip. The Journal of Bone and Joint Surgery 60(4): 432-443.

16. Mazur JM, Menelaus MB (1991) Neurologic status of spina bifida patients and the orthopedic surgeon. Clinical Orthopaedics and Related Research 264: 5464.

17. Johnson KL, Dudgeon B, Kuehn C, Walker W (2007) Assistive technology use among adolescents and young adults with spina bifida. Am J Public Health 97(2): 330-336.

18. Alatise OI, Adeolu AA, Komolafe EO, Adejuyigbe O, Sowande OA, et al. (2006) Pattern and factors affecting management outcome of spina bifida cystica in life, Nigeria. Pediatr Neurosurg 42(5): 277-83.

19. Rintoul NE, Sutton LN, Hubbard AM, Cohen B, Melchionni J, et al. (2002) A new look at myelomeningoceles: functional level, vertebral level, shunting, and the implications for fetal intervention. Pediatrics 109(3): 409-413.

20. Iborra J, Pages E, Cuxart A (1999) Neurological abnormalities, major orthopaedic deformities and ambulation analysis in a myelomeningocele population in Catalonia (Spain). Spinal Cord 37(5): 351-357.

21. Teulier C, Smith BA, Kubo M, Chang C, Moerchen V, et al. (2009) Stepping responses of infants with myelomeningocele when supported on a motorized treadmill. Phys Ther 89(1): 60-72.
22. Bartonek A (2010) Motor development toward ambulation in preschool children with myelomeningocele -a prospective study. Pediatric Phys Ther 22: 52-60.

23. Mazur JM, Kyle S (2004) Efficacy of bracing the lower limbs and ambulation training in children with myelomeningocele. Dev Med Child Neurol 46(5): 352356.

24. Ascani E, Bartolozzi P, Logroscino CA, Marchetti PG, Ponte A, et al. (1986) Natural history of untreated idiopathic scoliosis after skeletal maturity. Spine 11(8): 784-789.

25. Trivedi J, Thomson JD, Slakey JB, Banta JV, Jones PW (2002) Clinical and radiographic predictors of scoliosis in patients with myelomeningocele. J Bone Joint Surg Am 84(8): 1389-1394.

26. Brown JP (2001) Orthopaedic care of children with spina bifida: you've come a long way, baby! Orthop Nurs 20(4): 51-58.

27. Wright JG (2011) Hip and Spine Surgery is of Questionable Value in Spina Bifida: An Evidencebased Review. Clinical Orthopaedics \& Related Research 469(5): 1258-1264.

28. Dosa NP, Eckrich M, Katz DA, Turk M, Liptak GS, et al. (2007) Incidence, prevalence, and characteristics of fractures in children, adolescents, and adults with spina bifida. Journal of Spinal Cord Medicine 30: S5S9.

29. Thomson JD, Segal LS (2010) Orthopedic management of spina bifida Developmental Disabilities Research Reviews 16(1): 96-103.

30. Merkens MJ (2006) Guidelines for Spina Bifida health care services throughout the lifespan. Spina Bifida Association, (Ed.), $3^{\text {rd }}$ (Ed.), Washington DC.

31. Clayton DB, Brock JW, Joseph DB (2010) Urologic management of spina bifida. Developmental Disabilities Research Reviews 16(1): 88-95.

32. Verhoef M, Lurvink M, Barf HA, Post MW, Van Asbeck FW, et al. (2005) High prevalence of incontinence among young adults with spina bifida: description, prediction and problem perception. Spinal Cord 43(6): 331-340.

33. Dik P, Klijn AJ, Van Gool JD, De Jong-De Vos Van Steenwijk CCE, De Jong TPVM, et al. (2006) Early Start 


\section{Annals of Physiotherapy \& Occupational Therapy}

to Therapy Preserves Kidney Function in Spina Bifida Patients. European Urology 49(5): 908-913.

34. Hayes-Allen MC, Tring FC (1973) Obesity: another hazard for spina bifida children. Br J Prev Soc Med 27(3): 192-196.

35. Dosa NP, Foley JT, Eckrich M, Woodall-Ruff D, Liptak GS, et al. (2009) Obesity across the lifespan among persons with spina bifida. Disabil Rehabil 31(11): 914-920.

36. Mita K, Akataki K, Itoh K, Ono Y, Ishida N, et al. (1993) Assessment of obesity of children with spina bifida. Developmental Medicine \& Child Neurology 35(4): 305-311.

37. Buffart LM, Roebroeck ME, Rol M, Stam HJ, Van Den Berg-Emons RJ, et al. (2008) Triad of physical activity, aerobic fitness and obesity in adolescents and young adults with myelomeningocele. J Rehabil Med 40(1): 70-75.
38. Neter JE, Schokker DF, De Jong E, Renders CM, Seidell JC, et al. (2011) The Prevalence of Overweight and Obesity and Its Determinants in Children with and without Disabilities. J Pediatr 158(5): 735-739.

39. Department Of Health and Children (2011) Growing up in Ireland, National longitudinal study of children, Ireland.

40. Buffart LM, Westendorp T, Van Den Berg-Emons RJ, Stam HJ, Roebroeck ME, et al. (2009) Perceived barriers to and facilitators of physical activity in young adults with childhood-onset physical disabilities. J Rehabil Med 41(11): 881-885.

41. Reinehr T, Dobe M, Winkel K, Schaefer A, Hoffmann D, et al. (2010) Obesity in disabled children and adolescents: an overlooked group of patients. Deutsches Aerzteblatt International 107(15): 268275. 